\title{
A CLINICAL STUDY OF VENOUS ULCERS
}

\author{
Sriramoju Sreedhar ${ }^{1}$, Akula Nynasindhu², Lomte Naveen Kumar ${ }^{3}$
}

${ }^{1}$ Senior Resident, Department of General Surgery, Mahatma Gandhi Memorial Hospital, Warangal.

2Postgraduate Student, Department of General Surgery, Mahatma Gandhi Memorial Hospital, Warangal.

3Postgraduate Student, Department of General Surgery, Mahatma Gandhi Memorial Hospital, Warangal.

ABSTRACT

\section{BACKGROUND}

Venous ulcer is one of the most common cases presenting to surgery department. The nature of the disease makes it a morbid illness and profoundly affects the quality of life. This study is aimed at studying the distribution of the disease among various age groups, sex and occupation. It also studies the clinical features and treatment modalities.

\section{MATERIALS AND METHODS}

Fifty patients with venous leg ulcers were included in the study. Clinical history and physical examination of the ulcer and the venous system of leg were done, and patients were subjected to duplex scan.

\section{RESULTS}

The male-to-female ratio was noted to be 15: $1.90 \%$ were found to be manual labourers in our study. Varicosity is the most common aetiology for venous ulcer of the leg. The common associations of ulcer are varicosity (100\%), hyperpigmentation (68\%) followed by oedema and pain. Incidence of venous ulcer was almost same on both sides.

\section{CONCLUSION}

Male preponderance was observed in my study and manual labourers were the majority affected by venous ulcer. Most common association to ulcer was varicosity. Surgery showed promising healing rates in my study and no recurrence in follow-up period. Healing rates are promising in cases treated surgically along with ambulatory compression therapy when compared to ambulatory compression therapy alone. Aetiology of ulcers, age group of patients does not significantly interfere in healing of ulcers.

\section{KEYWORDS}

Venous Ulcer, Varicose Veins.

HOW TO CITE THIS ARTICLE: Sreedhar S, Nynasindhu A, Kumar LN. A clinical study of venous ulcers. J. Evolution Med. Dent. Sci. 2018;7(05):603-607, DOI: $10.14260 /$ jemds/2018/137

\section{BACKGROUND}

Venous ulcers are not a new problem. They are well known to have plagued humankind since ancient times. The first written description of treatment of probable venous ulcers was found in the Papyrus of Eber originating from Egypt around 1550 BC. In the Milan Cathedral in Italy, four big paintings show miracles performed by Saint Carlo for patients with leg ulcers in the beginning of the $17^{\text {th }}$ century. ${ }^{1}$

The chronic venous leg ulcer is defined as an ulcer distal to the knee, caused mainly by venous dysfunction which does not heal within six weeks. ${ }^{2}$ They occur as a late consequence of chronic ambulatory venous hypertension, which is caused by outflow obstruction and reflux due to superficial or deep venous incompetence. ${ }^{3}$

Ever since its known incidence had been increasing, which comprises about $60 \%-70 \%$ of all ulcers in the lower leg.

The classical presentation of a venous leg ulcer is an irregularly shaped partial thickness wound with well-defined borders surrounded by erythematous or hyperpigmented

'Financial or Other Competing Interest': None.

Submission 05-01-2018, Peer Review 20-01-2018,

Acceptance 22-01-2018, Published 29-01-2018.

Corresponding Author:

Sriramoju Sreedhar,

\#3-1-72, Kavitha Clinic,

Ganesh Street,

Jangoan.

E-mail: drsridhar2506@gmail.com

DOI: $10.14260 /$ jemds $/ 2018 / 137$

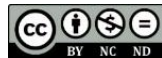

indurated skin. Venous ulcers vary in size and location but are most common on the distal medial aspect just above the medial malleolus (Gaiter area). The prevalence of non-healing leg ulcers varies in different published reports. ${ }^{2}$

The point prevalence is likely to be in the region of $0.1 \%$ $0.3 \%{ }^{4}$ The prevalence increases dramatically with age. More than $1 \%-3 \%$ of the patients are over the age of 60 years. ${ }^{5}$

Despite the high prevalence of venous ulcer, it is often neglected or managed inadequately and thus has a significant socioeconomic impact in terms of medical care, days off work and reduced quality of life.

As there are various treatment modalities available, it is essential to individualise the treatment for every patient so as to ensure comprehensive care and effective wound closure.

A multidisciplinary approach with different medical specialists such as a dermatologist, vascular surgeon, plastic surgeon, well-trained nurses have demonstrated increased healing rates with decreased recurrences. ${ }^{6}$

Though important advances have been made in the management of leg ulcers, India lags far behind the standards set by the European countries. Treatment is fragmented, poorly taught and inadequately researched. The average time taken to heal an ulcer is about six months and some persist for years. Good management depends on accurate diagnosis, simple and appropriate care of the wound and treatment of underlying cause.

A limited number of studies have investigated in detail the clinical study and management of venous ulcer, especially in rural setup. This study aims to provide information on the management of venous leg ulcer in rural setup. 


\section{Aims and Objectives}

1. To study the aetiology of venous ulcers of lower limb.

2. To study the age and sex distribution of venous ulcers of lower limb.

3. To study the effect of occupation on the incidence of venous ulcers of lower limb.

4. To study the treatment modalities of venous ulcers and its outcome.

\section{MATERIALS AND METHODS}

\section{Source of Data}

This is a descriptive study. Data was collected through a prescribed proforma from the patients admitted in Department of General Surgery, Kakatiya Medical College and MGM Hospital with clinical diagnosis of venous leg ulcers during the period from December 2015 to October 2017.

\section{Method of Collection of Data}

This study was a descriptive study conducted in MGM Hospital. All the cases which satisfy the inclusion criteria will be included in the study. Informed consent will be taken and the history, clinical, imaging and laboratory parameters will be recorded in predesigned data sheet.

\section{Sample Size}

50 cases of venous leg ulcers admitted to Surgical Department of MGM Hospital during the period from December 2015 to October 2017. Among 50 patients who had venous ulcerations, 50 patients were due to varicose veins and of them 2 patients had DVT. A detailed history including symptoms, duration of ulcer, mode of development, occupation and previous surgery were taken. The patients were examined in both standing and recumbent postures. The location, size, floor of the ulcer and secondary changes in the leg including pigmentation and mobility of ankle joint were noted. Legs were examined individually for varicosities. Saphenofemoral/ Saphenopopliteal and perforator incompetences were made out by Trendelenburg, multiple tourniquet test and Schwartz test. Deep vein was assessed by modified Perthes test. Perforator incompetences were localised by palpating the deep fascia for defects. Arterial pulses of both feet were examined to rule out arterial components. Abdominal and pelvic examination were done to rule out tumours, dilated suprapubic veins and ascites. Doppler and Duplex imaging was used to rule out DVT and localise perforator incompetence in all cases. Routine investigations of blood were done. Swab taken from the wound and antibiotics were prescribed according to culture and sensitivity. Patients were treated with initial Hydrogen Peroxide and Povidone Iodide until wound became healthy and then normal saline dressing was done daily. Elastocrepe bandage was applied from the level of head of metatarsal up to the knee. The limb was kept elevated by raising the foot end of the bed. 46 patients underwent surgery. The choice of surgery was determined by the extent of disease and patient's general condition.

The procedures done included Trendelenburg operation, complete stripping of long saphenous vein and subfascial ligation of perforators under spinal anaesthesia. After performing the surgery, a layer of pad and cotton bandage was applied over which Elastocrepe bandage was also applied. The dressings were changed on the 3rd POD. Patient was allowed to walk after 12 hours. The sutures were removed after 10 days. They were advised to avoid prolonged standing and to wear Elastocrepe bandage for 6 months and come for follow-up after 2 - 3 weeks.

\section{Inclusion Criteria}

All the patients admitted with clinical diagnosis of venous leg ulcers above 18 years admitted to Surgical Department of MGM Hospital.

\section{Exclusion Criteria}

Patients not willing to give consent for study, proven cases of arterial ulcers, traumatic ulcers. Diabetic ulcers, ulcers due to malignancy and neuropathic ulcers.

\section{Follow-Up}

3 months.

\section{RESULTS}

In the present study, the majority of patients with Venous Leg Ulcers were in the age group of $21-40 \mathrm{yrs}$. and $41-60 \mathrm{yrs}$. which constituted $60 \%$ and $34 \%$ respectively. The youngest patient was 21 years old and the oldest was 67 years old with mean age of 39.7. In the present study, 47 cases were male which constituted $94 \%$ and 3 were female which constituted $6 \%$. In the present study, $90 \%$ were manual labourers and $8 \%$ were policemen. One patient in our group was housewife. In the present study, incidence of venous ulcer on left leg is $46 \%$ and on right leg is $48 \%$ and bilaterally $6 \%$. In the present study ulcer was the most common symptom noted in all 50 cases (100\%) with varicose veins present in 94\% (47 cases), associated pain in 54\% (27 cases), oedema of leg in $6 \%$ (3 cases). Of the 50 venous ulcer discharges' culture sensitivity, E. coli were found in $14 \%$ and Staphylococcus aureus in $32 \%$ each; no growth in $28 \%$ of cases. Of the 50 cases, long saphenous varicosity was noted in $90 \%$ cases, short saphenous varicosity in $6 \%$, combined short and long system varicosity in $4 \%$, bilaterality $4 \%$ and DVT $4 \%$.

Of the 50 venous ulcers, $8 \%$ ( 4 cases) of cases were managed conservatively and $92 \%$ (46 cases) were managed surgically, i.e. Trendelenburg operation in $76 \%$ (38 cases), subfascial ligation of perforators in 78\% (39 cases) and SSV ligation in $6 \%$ (3 cases). Both cases of DVT were managed conservatively. 12 cases underwent skin grafting who had ulcers for more than 4 months. Wound infection was noted in $16 \%$ ( 8 cases), haematoma in $4 \%$ ( 2 cases). Wound gaping was seen in $8 \%$ ( 4 cases).

\section{DISCUSSION}

The incidence of venous leg ulcer and the aetiological factors are studied from the patients admitted in MGM Hospital and the data regarding the signs and symptoms, laboratory and radiological investigations are analysed from the fifty cases admitted to our hospital between December 2015 and October 2017. 


\begin{tabular}{|c|c|c|c|}
\hline Age Incidence & $\begin{array}{c}\text { Abbade } \\
\text { et al }^{7}\end{array}$ & $\begin{array}{c}\text { O Nelzen } \\
\text { et al }^{\mathbf{8}}\end{array}$ & $\begin{array}{c}\text { Present } \\
\text { Study }\end{array}$ \\
\hline Age (Range) yrs. & $57(24-85)$ & $39-97(68)$ & $40.7(21-68)$ \\
\hline $20-40$ yrs. & $6.7 \%$ & $2 \%$ & $60 \%$ \\
\hline $41-60$ yrs. & $49.1 \%$ & $9 \%$ & $34 \%$ \\
\hline$>61$ yrs. & $44.2 \%$ & $90 \%$ & $6 \%$ \\
\hline \multicolumn{4}{|c|}{ Table 1. Age Incidence } \\
\hline
\end{tabular}

In our study, maximum cases were in the middle age group (20 - 40 yrs.). Mean age of patients in our study was 40.7 yrs., whereas in Abbade et al it was 57 yrs. In another study by KK Sethia, ${ }^{9}$ mean age of patients with venous ulceration was 55.4 yrs.

In the study by 0 Nelzen,,$^{8} 61 \%$ of all patients experienced their first ulcer episode before age of 65 yrs. There is no statistical significance between age of patient and the healing of ulcers in the present study.

\begin{tabular}{|c|c|c|c|c|c|}
\hline $\begin{array}{c}\text { Sex } \\
\text { Incidence }\end{array}$ & $\begin{array}{c}\text { Abbade } \\
\text { et al }^{7}\end{array}$ & $\begin{array}{c}\text { O Nelzen } \\
\text { et al }^{\mathbf{8}}\end{array}$ & $\begin{array}{c}\text { KK } \\
\text { Sethia } \\
\text { et al }\end{array}$ & $\begin{array}{c}\text { SR } \\
\text { Baker } \\
\text { et al } \mathbf{1 0}\end{array}$ & $\begin{array}{c}\text { Present } \\
\text { Study }\end{array}$ \\
\hline Male & $25 \%$ & $33 \%$ & $52 \%$ & $35 \%$ & $94 \%$ \\
\hline Female & $75 \%$ & $67 \%$ & $48 \%$ & $65 \%$ & $6 \%$ \\
\hline M:F & $1: 3$ & $1: 5$ & $1: 0$ & $1: 1.8$ & $15: 1$ \\
\hline \multicolumn{5}{|c|}{ Table 2. Sex Incidence } \\
\hline
\end{tabular}

According to the study by Scott et al, below 60 yrs. of age $\mathrm{M}: \mathrm{F}=2.4: 1$, above 60 yrs. of age $\mathrm{M}: \mathrm{F}=1: 1.2$. In our study, the majority of cases were males contributing to $94 \%$. Whereas studies by Abbade et al, O Nelzen et al, KK Sethia et al and SR Baker et al showed female preponderance.

\begin{tabular}{|c|c|c|c|}
\hline & Right & Left & Bilateral \\
\hline Abbade et al $^{7}$ & $55.8 \%$ & $58.3 \%$ & $15 \%$ \\
\hline SR Baker et al $^{10}$ & $44 \%$ & $56 \%$ & $15 \%$ \\
\hline O Nelzen $^{8}$ & $35 \%$ & $44 \%$ & $21 \%$ \\
\hline Present Study & $48 \%$ & $46 \%$ & $6 \%$ \\
\hline \multicolumn{3}{|c|}{ Table 3. Laterality } \\
\hline
\end{tabular}

In a study by Abbade et al, $58.3 \%$ of patients presented with an ulcer on left leg and $55.8 \%$ on right leg, $15 \%$ of these were bilateral ulcers. In another study by SR Baker et al, $56 \%$ of cases had ulcers on left leg, $44 \%$ on right leg and $15 \%$ of these were bilateral. Similarly, in a study by 0 Nelzen et al, 8 ulcers on left leg accounted for $44 \%, 35 \%$ on right leg and $21 \%$ bilaterally. In our study, $48 \%$ were in right leg and $46 \%$ were in left leg.

\begin{tabular}{|c|c|c|c|c|c|c|}
\hline & $\frac{\grave{d}}{\square}$ & 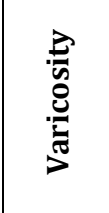 & $\Xi$ & 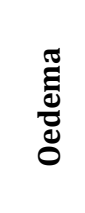 & 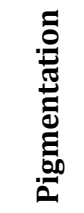 & \\
\hline $\begin{array}{c}\text { Abbade } \\
\text { et al } 7\end{array}$ & $100 \%$ & $86.6 \%$ & NA & NA & NA & NA \\
\hline $\begin{array}{c}\text { J Saarinen } \\
\text { et al } 11\end{array}$ & $100 \%$ & NA & $81 \%$ & $86 \%$ & NA & $19 \%$ \\
\hline O Nelzen ${ }^{8}$ & $100 \%$ & NA & $28 \%$ & NA & NA & NA \\
\hline $\begin{array}{c}\text { Present } \\
\text { Study }\end{array}$ & $100 \%$ & $94 \%$ & $54 \%$ & $6 \%$ & $68 \%$ & $60 \%$ \\
\hline \multicolumn{7}{|c|}{ Table 4. Symptoms } \\
\hline
\end{tabular}

According to Abbade $^{7}$ varicose veins were noted in $86.6 \%$ of patients with venous ulcers, J Saarinen's ${ }^{11}$ study showed that in patients with venous ulcerations pain in $81 \%$, oedema in $86 \%$ and itching in $19 \%$ of cases noted. 0 Nelzen showed venous ulcers were painful in $31 \%$ of cases. ${ }^{8}$

\begin{tabular}{|c|c|}
\hline Present Study & Randall et al ${ }^{12}$ \\
\hline Staph. aureus, 32\% & Staph. aureus, $41.5 \%$ \\
\hline E. coli, $14 \%$ & E. coli, $6.9 \%$ \\
\hline Klebsiella sp. $10 \%$ & Streptococci \\
\hline Pseudomonas 8\% & Bacteroides \\
\hline Mixed 8\% & - \\
\hline No growth $28 \%$ & - \\
\hline \multicolumn{2}{|c|}{ Table 5. Organism Cultured } \\
\hline
\end{tabular}

In the present study, most common organisms cultured from the venous ulcer discharge was Staph. aureus accounting for $32 \%$. Whereas according to Joseph Gray et al, in venous leg ulcers the most common organism included are Staphylococcus aureus, Pseudomonas aeruginosa and Betahaemolytic streptococci. In another study by Randall et al, Staphylococcus aureus in $41.5 \%$ and E. coli in $6.9 \%$ cases.

\begin{tabular}{|c|c|c|c|}
\hline & Varicosity & DVT & $\begin{array}{c}\text { Past h/o } \\
\text { Venous Surgery }\end{array}$ \\
\hline Abbade et al ${ }^{7}$ & $86.6 \%$ & $10.8 \%$ & $\mathrm{NA}$ \\
\hline SR Baker et al 10 & $57 \%$ & $17 \%$ & $30 \%$ \\
\hline O Nelzen $^{8}$ & $100 \%$ & $37 \%$ & $24 \%$ \\
\hline Present Study & $100 \%$ & $4 \%$ & NA \\
\hline
\end{tabular}

In a study by Abbade et al, 7 in patients with venous ulcer varicose veins were found in $86.6 \%$ cases and h/o DVT was reported in $10.8 \%$ of cases. In another study by SR Baker et al, 10 venous insufficiency was noted in $57 \%$, h/o DVT was present in $17 \%$ of cases, h/o previous venous surgery was present in $30 \%$ of cases. Similarly, in a study by 0 Nelzen et al, venous insufficiency was noted in $100 \%$ of cases, $24 \%$ of cases had h/o previous venous surgery. ${ }^{8}$ In our study, all cases had varicosity and $4 \%$ had DVT.

\begin{tabular}{|c|c|c|c|}
\hline & $\begin{array}{c}\text { Long } \\
\text { Saphenous }\end{array}$ & $\begin{array}{c}\text { Short } \\
\text { Saphenous }\end{array}$ & Combined \\
\hline $\begin{array}{c}\text { Nicos Labropoulos } \\
\text { et al } 13\end{array}$ & $61 \%$ & $9 \%$ & $30 \%$ \\
\hline J Saarinen et al 11 & $83 \%$ & $2 \%$ & $\mathrm{NA}$ \\
\hline Present Study & $90 \%$ & $6 \%$ & $4 \%$ \\
\hline \multicolumn{3}{|c|}{ Table 7. Venous System Involved } \\
\hline
\end{tabular}

In the present study, on examination long saphenous varicosity was noted in $90 \%$, short saphenous varicosity in $6 \%$, combined short and long system varicosity in $4 \%$. These findings were similar to the study by J Saarinen et al,11 long saphenous involvement in $83 \%$ cases, short saphenous involvement in $2 \%$ cases. Whereas in a study by Nicos Labropoulos et al,13 long saphenous varicosity was seen in $61 \%$, short saphenous varicosity in $9 \%$, combined in $30 \%$ cases.

\section{Treatment Aspect}

In the present study, $8 \%$ of cases were managed conservatively and $92 \%$ were managed surgically, i.e. Trendelenberg operation in $76 \%$, subfascial ligation of perforators in $78 \%$ and SSV ligation in $6 \%$. 
At the follow-up at 3 - 6 wks, $70 \%$ of cases had completely healed ulcers which included all cases which underwent skin grafting and 30\% showed decrease in ulcer size. At 3 months follow-up of surgically treated cases showed $100 \%$ healing, whereas 3 of 4 cases conservatively managed showed healing.

Alfred Obermayer et al $^{13}$ concluded in his study that venous surgery is possible and indicated at any stage, whether years of conservative therapy have failed or whether patients have an ulceration for only a few weeks. Ralph de Palma et al $^{14}$ concluded in his study that non-operative treatment even in skilled hands is associated with prolonged disability and recurrence, which can be improved significantly with operative intervention. According to the study by $\mathrm{V}$ Jankunas et al, ${ }^{15}$ skin grafting positively influences quality of life by fastening the healing rate of ulcer, also reduce the total expenditure of ulcer treatment. FT Padberg et $\mathrm{a}^{16}$ in his study concluded that external compression technique retains a substantial role in the management of venous ulceration, but success is directly related to patient's adherence/ compliance to the treatment regimen. Healing of 93\% was achieved by simple, straight forward regimen of daily cleaning and elastic compression in University of Oregon and 92\% healing at Wisconsin Medical College.

According to M Guest et al,17 in the treatment of venous ulceration superficial venous surgery gives no additional benefit to compression therapy in healing of ulcer. Wijn et $\mathrm{al}^{18}$ in his study concluded that patients with medial and recurrent ulceration should receive surgery combined with compression therapy. According to the Eschar study by Jamie Barwell et $\mathrm{al}^{19}$ healing rates were similar in the compression + surgery group and compression group, but recurrence rates were significantly reduced in compression + surgery group.

Although, almost any varicose veins can be treated by surgery, not all patients will want to have open surgery. In spite of its current status as gold standard, it is inevitable that the role of standard surgery in the treatment of lower limb varicose veins will shrink significantly in nearest future, in line with expansion of minimally invasive techniques.

\section{Summary}

- Though venous ulceration is described as a disease of elderly, it is also found equally common among young adults in my study.

- $\quad$ Male: Female incidence is 15: 1. Females here are more homebound and they can relax more in between their working hours, thereby reducing the risk of varicosity and its complications.

- Varicosity is the most common aetiology for venous leg ulcer.

- DVT as a cause of venous ulcer as per my study is only $4 \%$.

- Manual labourers are predisposed to venous ulceration.

- The common associations of ulcer are varicosity (100\%), hyperpigmentation (68\%) followed by oedema and pain, especially on prolonged standing which is relieved by keeping legs elevated.

- Incidence of venous ulcer was almost same on both sides.

- Single ulcer, shallow with serous discharge is most common.
- Healing rates are promising in cases treated surgically, aetiology of ulcers, age group of patients does not significantly interfere in healing of ulcers.

- In the follow-up period of three months to one and a half years, there was no incidence of recurrence.

\section{CONCLUSION}

- In this study, we observed people from rural setup come to hospital when the symptoms are severe.

- This study revealed that the most common association to venous ulcers of lower limb is varicose veins.

- This study revealed that the disease is prevalent in active phase of life and male preponderance.

- Occupations involving prolonged standing and violent muscular effort are prone for the disease.

- Majority of the patients had long saphenous vein incompetence and complications are more when both valvular and perforator systems are involved.

- Compression stockings alone may be appropriate for patients who are too unfit for intervention or those who do not wish to have any form of surgical intervention.

- Conventional open surgery has also improved with Duplex mapping, smaller incisions and better outcomes.

\section{REFERENCES}

[1] Nelzen 0. Epidemiology of venous ulcers. Venous Ulcers 2007;3:27-41.

[2] Nelzen O, Berggvist D, Lindhagen A. Leg ulcer etiologya cross sectional population study. Journal of Vascular Surgery 1991;14(4):557-64.

[3] Brizzio E, Amsler F, Lun B, et al. Comparison of low strength compression stockings with bandages for the treatment of recalcitrant venous ulcers. Journal of Vascular Surgery 2010;51(2):410-6.

[4] Nelzen 0. Prevalence of venous leg ulcer: the importance of data collection method. Phlebolymphology 2008;15(4):143-50.

[5] Bolton LL. Venous ulcers, WHO's wound and lymphoedema management 2009;9:103-7.

[6] Lopez AP, Phillips TJ. Venous ulcers. Wounds 1998;10(5):149-57.

[7] Abbade LPF, Lastoria S, de Almeida $\mathrm{RH}$, et al. A sociodemographic, clinical study of patients with venous ulcer. International Journal of Dermatology 2005;44(12):989-92.

[8] Nelzen 0, Berggvist D, Lindhagen A. Venous and nonvenous leg ulcers: clinical history and appearance in a population study. British Journal of Surgery 1994;81(2):182-7.

[9] Sethia KK, Darke SG. Long saphenous incompetence as a cause of venous ulceration. British Journal of Surgery 1984;71(10):754-5.

[10] Baker SR, Stacey MC, Jopp-McKay AG, et al. Epidemology of chronic venous ulcers. British Journal of Surgery 1991;78(7):864-7.

[11] Saarinen J, Heikkinen M, Suominen V, et al. Symptoms, clinical disability scores and reflux in complicated and uncomplicated primary varicose veins. Phlebology: The Journal of Venous Disease 2003;18(2):73-7. 
[12] Wolcott RC, Gontcharova V, Sun Y, et al. Evaluation of the bacterial diversity among and within individual venous leg ulcers using bacterial tag-encoded FLX and titanium amplicon pyrosequencing and metagenomic approaches. BMC Microbiology 2009;9:226.

[13] Labropoulos N, Leon M, Geroulakos G, et al. Venous haemodynmic abnormalities in patients with leg ulceration. The American Journal of Surgery 1995;169(6):572-4.

[14] De Palma RG, Kowallek DL. Venous ulceration: a crossover study from non-operative to operative treatment. J Vasc Surg 1996;24(5):788-92.

[15] Jankunas V, Bagdonas R, Samsanavicius D, et al. The influence of surgical treatment for chronic leg ulcers on the quality dynamics of the patient's life. Acta Chir Belg 2007;107(4):386-96.
[16] Padberg FT. Surgical intervention in venous ulceration. Journal of Cardiovascular Surgery 1999;7(1):83-90.

[17] Guest M, Smith JJ, Tripuraneni G, et al. RCT of varicose vein surgery with compression vs compression alone for the treatment of venous ulceration. Phlebology: The J of Venous Disease 2003;18(3):130-6.

[18] Van Gent WB, Hop WC, van Praag MC, et al. Conservative vs surgical treatment of venous leg ulcers: a prospective, randomized, multicenter trial. Journal of Vascular Surgery 2006;44(3):563-71.

[19] Barwell JR, Davies CE, Deacon J, et al. Comparison of surgery and compression with compression alone in chronic venous ulceration (ESCHAR study): randomized controlled trial. The Lancet 2004;363(9424):1854-9. 